\title{
Desarrollo y validación de una reacción en cadena de la polimerasa múltiple para la identificación de los serogrupos B, C2, D y E de Salmonella enterica
}

\author{
Lelia Lavalett ${ }^{1,2}$, Miryan Margot Sánchez², Nélida Múñoz ${ }^{3}$, Jaime Moreno³, \\ Nora Cardona-Castro ${ }^{2}$
}

\author{
1 Maestría en Biotecnología, Universidad Nacional de Colombia, Medellín, Colombia \\ 2 Instituto Colombiano de Medicina Tropical-Universidad CES, Medellín, Colombia \\ ${ }^{3}$ Grupo de Microbiología, Subdirección de Investigación, Instituto Nacional de Salud, Bogotá, D.C., \\ Colombia
}

Introducción. El esquema Kaufmann-White para la serotipificación de Salmonella, reconoce 46 antígenos $\mathrm{O}$ y 119 antígenos $\mathrm{H}$, los cuales han permitido la caracterización de 2.541 serovares. La serotipificación es una herramienta epidemiológica útil en la identificación de serovares circulantes y estudio de brotes, sin embargo, presenta limitaciones técnicas, de interpretación de resultados y alto costo.

Objetivo. Desarrollar una prueba de reacción en cadena de la polimerasa múltiple (PCR-M) como alternativa para identificar los serogrupos B, C2, D y E de Salmonella enterica.

Materiales y métodos. Se desarrolló una PCR-M para detectar los genes $r f b J$ de los serogrupos B y C2 y wzx de los serogrupos D y E. Para estandarizar la PCR-M se probaron cepas de referencia de Salmonella pertenecientes a los serogrupos de estudio. Se incluyó el gen invA específico del género Salmonella como control interno de amplificación. La técnica fue validada con un estudio ciego que incluyó 400 aislamientos de Salmonella previamente serotipificados.

Resultados. La PCR-M permitió identificar los serogrupos de Salmonella con resultados reproducibles (índice kappa=0,95). La sensibilidad de la prueba estuvo entre $98 \%$ y $100 \%$ y la especificidad entre $96 \%$ y $100 \%$.

Conclusiones. El polimorfismo de los genes rfbJ y wzx permitió desarrollar un método de tipificación molecular sensible, específico y reproducible, que podría servir de apoyo a la serotipificación para identificar serogrupos de Salmonella.

Palabras clave: Salmonella enterica, serogrupos, serotipificación, tipificación molecular, PCR múltiple.

\section{Development and validation of a multiplex polymerase chain reaction for molecular identification of Salmonella enterica serogroups B, C2, D and E}

Introduction. The scheme Kauffman-White $(\mathrm{KW})$ for serotyping of Salmonella recognizes $46 \mathrm{O}$ antigens, and $119 \mathrm{H}$ antigens, thereby permitting the characterization of 2,541 serotypes. The serotyping is a useful epidemiological tool in identifying circulating serotypes and to characterize outbreaks. However, the method presents technical limitations, difficulty in interpretation of results and high costs.

Objective. A multiplex polymerase chain reaction test (M-PCR) was developed as an alternative method for the identification of serogroups B, C2, D, and E of Salmonella enterica.

Materials and methods. The M-PCR detected Salmonella genes rfbJ of serogroups B and C2 and wzx of serogroups D and E. To standardize the M-PCR, reference strains of Salmonella serogroups were compared. Amplification of invA gender-specific gene of Salmonella was included as internal control of amplification. To validate the test, a blind study was conducted to identify by M-PCR 400 isolates that had been previously characterized by serology.

Results. The M-PCR detected Salmonella serogroups with reproducible results (Kappa index $=0.95$ ). The sensitivity of the test was between $98 \%$ to $100 \%$ and specificity between $96 \%$ to $100 \%$. 
Conclusions. The polymorphisms in the Salmonella genes rfbJ and wzx permitted the development of a method for molecular typing of Salmonella serogroups that was sensitive, specific and reproducible.

Key words: Salmonella enterica, serogroups, serotyping, molecular typing, multiplex PCR.

La serotipificación de Salmonella spp. basada en el esquema Kaufmann-White reconoce 46 antígenos $\mathrm{O}$ y 119 antígenos $\mathrm{H}$, los cuales han permitido la caracterización de 2.541 serotipos. Es un método ampliamente utilizado con fines epidemiológicos, que identifica los serovares prevalentes en cada región y la etiología de brotes e infecciones en humanos y animales (1-3).

La variación del antígeno $O$ de Salmonella spp. es consecuencia de la diversidad genética dentro del grupo de genes $r f b$, los cuales codifican las enzimas involucradas en la biosíntesis y el ensamble de este antígeno (4-7). Por otra parte, la proteína WZX es característica del grupo de antígenos $\mathrm{O}$ y es codificada por el gen wzx; esta proteína es una flipasa utilizada para la translocación de la unidad $O$ fuera de la membrana (8). La detección de estos antígenos es la base de la serotipificación con antisueros específicos, de los cuales se derivan las fórmulas antigénicas que caracterizan cada serogrupo (1).

Aunque la serotipificación es un método ampliamente utilizado en estudios epidemiológicos con buen poder discriminatorio, presenta limitaciones tales como la necesidad de más de 250 tipos de antisueros diferentes (1,3); los antisueros comerciales son costosos, con disponibilidad limitada y calidad variable para los antígenos menos comunes. Por otra parte, la generación de los resultados toma de tres a cinco días y, aproximadamente, $5 \%$ a $8 \%$ de los aislamientos son parcialmente tipificados, debido a que existen cepas rugosas que no expresan antígenos en la superficie, encapsuladas, y otras

\footnotetext{
Correspondencia:

Nora Cardona-Castro, Instituto Colombiano de Medicina Tropical, Carrera 43A № 52 sur-99, Sabaneta, Colombia. Teléfono: (574) 305 3500, extensión 2297; fax: (574) 301 4258

ncardona@ces.edu.co
}

Recibido: 14/10/08; aceptado:16/12/08 que no expresan los antígenos flagelares de las fases 1 y 2 (9). Por lo anterior, y debido a la dificultad en la interpretación de los resultados, la aplicación de la serotipificación está limitada a los laboratorios de referencia.

En respuesta a estas limitaciones, se han desarrollado en los últimos años métodos moleculares basados en la PCR que permiten la detección directa de los genes que codifican para los antígenos somáticos $\mathrm{O}$ y flagelares $\mathrm{H}$ (10-13). Las ventajas de los métodos moleculares descritos frente a la serotipificación es que son costo-efectivos, fáciles de estandarizar, muy sensibles, específicos, rápidos, reproducibles, independientes del uso de antisueros y no necesitan que se expresen los antígenos (9-13).

La técnica de PCR es un método rápido que posee ventajas inherentes que la caracterizan y, por ende, es un excelente método aplicable a la detección e identificación de Salmonella spp. y de otros patógenos. Además, las cepas carentes de antígenos somáticos $(\mathrm{O})$ o flagelares $(\mathrm{H})$ (cepas rugosas), que sólo son reconocidas como Salmonella spp. por el método tradicional de serotipificación, pueden identificarse mediante PCR, debido a que esta técnica detecta secuencias específicas de ADN y no se altera por las variaciones fenotípicas que se pueden evidenciar por patrones bioquímicos.

Este trabajo presenta una alternativa para determinar los serogrupos de Salmonella mediante el uso de diferentes iniciadores a los ya informados en la literatura para el antígeno $\mathrm{O}$ (genes $r f b$ y $w z x$ ), teniendo como referencia el polimorfismo de estos antígenos, los cuales permiten la identificación de los grupos B, C2, D y E de Salmonella enterica, serogrupos más prevalentes en Colombia aislados de muestras clínicas humanas y de alimentos (14). La identificación molecular del serogrupo permite de manera rápida la determinación de los posibles serovares implicados en el cuadro 
clínico o en el brote en estudio, resultado que apoya la serotipificación de una manera rápida y precisa.

\section{Materiales y métodos}

\section{Aislamientos bacterianos}

Seutilizaron 18 cepas yaislamientos de referencia correspondientes a los cuatro serogrupos del estudio, a los cuales se les realizó la descripción antigénica según el esquema Kaufmann-White (cuadro 1). Como controles negativos de especificidad de la prueba, se usaron cepas diferentes al género Salmonella: Escherichia coli, Proteus spp., Klebsiella spp., Citrobacter spp., Shigella sp., Yersinia spp., y Aeromonas spp. Estas cepas pertenecen a la colección del laboratorio del Grupo de Microbiología del Instituto Nacional de Salud de Colombia, las cuales se conservaron a temperatura ambiente sembradas por punción en agar IP (Instituto Pasteur, París, Francia).

\section{Extracción de ADN}

Para recuperar cada una de las cepas, se retiró material con un asa del tubo original, la cual fue sembrada en agar Mueller Hinton® (Becton Dickinson, Franklin Lakes, New Jersey, USA), e incubado por 24 horas a $37^{\circ} \mathrm{C}$. EI ADN fue extraído por el método de lisis con solución detergente (Tris $\mathrm{HCl} 10 \mathrm{mM}$, EDTA $1 \mathrm{mM} \mathrm{pH}$ 8,0, Triton X-100 0,2\%), descrito por Haque y colaboradores (15). Este material se conservó a $-20^{\circ} \mathrm{C}$ hasta ser utilizado en la PCR. Se determinó la relación de absorbancias a 260/280 $\mathrm{nm}$ por espectrofotometría (Spectronic Genesys 2, Bath UK).

\section{Diseño de los iniciadores}

Para el estudio se diseñaron iniciadores para los genes rfb y wzx, y se hizo una revisión bibliográfica y búsqueda de las secuencias de los genes en las bases de datos GenBank (http:// www.ncbi.nlm.nih.gov/Genbank/index.html), European Molecular Biology Laboratory (EMBL) (http://www.ebi.ac.uk/embl/Access/index.html) y DNA Data Bank of Japan (DDBJ) (http://www. ddbj.nig.ac.jp/intro-e.html).

Se utilizó el programa Primer 3, teniendo en cuenta los siguientes parámetros: longitud de

Cuadro 1. Descripción antigénica según Kauffman-White de cepas de referencia de los serogrupos de Salmonella propuestos en este estudio para identificar por PCR múltiple.

\begin{tabular}{|c|c|c|c|}
\hline Serogrupo & Serotipo & Fórmula antigénica & Referencia \\
\hline B & $\begin{array}{l}\text { Derby } \\
\text { Typhimurium } \\
\text { Heidelberg } \\
\text { Saintpaul }\end{array}$ & $\begin{array}{l}\text { 1,4,5,12:f,g: }[1,2] \\
\text { 1,4,5,12:I:1,2 } \\
\text { 1,4,5,12:r:1 } \\
\text { 1,4,5,12: e, h:1,2 }\end{array}$ & $\begin{array}{c}\text { CDC } 2 \\
\text { CDC 21--IX-66 } \\
\text { CDC 16 } \\
\text { INS 29-371-06 }\end{array}$ \\
\hline D & $\begin{array}{l}\text { Typha } \\
\text { Enteritidis } \\
\text { Dublin } \\
\text { Gallinarum }\end{array}$ & $\begin{array}{l}\text { 1,9,12:d:- } \\
\text { 1,9,12:g,m:- } \\
\text { 1,9,12:g,p:- } \\
\text { 1,9,12:-:- }\end{array}$ & $\begin{array}{c}\text { CDC } 57 \\
\text { CDC } 64 \\
\text { CDC 65 } \\
\text { INS 03-122-02 }\end{array}$ \\
\hline E & $\begin{array}{l}\text { Anatum } \\
\text { Uganda } \\
\text { Muenster } \\
\text { Sinstorff } \\
\text { Weltevreden }\end{array}$ & $\begin{array}{l}3,10: e, h: 1,7 \\
3,10: I: Z 13: 1,5 \\
3,10: e, h: 1,5 \\
3,10: \text { I,v:1,5 } \\
\text { 3,10: r,z6:- }\end{array}$ & $\begin{array}{c}\text { CDC } 287 \mathrm{~b} 2 \mathrm{~K} \\
\text { CDC X-26-66 } \\
\text { CDC } 2 \\
\text { CDC 1/V-4-94 } \\
\text { INS 4-60-06 }\end{array}$ \\
\hline $\mathrm{C} 2$ & $\begin{array}{l}\text { Muenchen } \\
\text { Hadar } \\
\text { Manhattan } \\
\text { Kentucky } \\
\text { Newport }\end{array}$ & $\begin{array}{l}\text { 6,8: d:1,2 } \\
\text { 6,8:z10:e,n,x } \\
6,8: d: 1,5 \\
\text { 8,20: I,z6:- } \\
\text { 6,8:e,h:1,2 }\end{array}$ & $\begin{array}{c}\text { INS 18-194-03 } \\
\text { INS 147-03 } \\
\text { INS } 1 \\
\text { CDC } 2865-56 \\
\text { INS 155-00 }\end{array}$ \\
\hline
\end{tabular}

CDC: Centers for Disease Control and Prevention; INS: colección del Instituto Nacional de Salud, Colombia. 
20 a $30 \mathrm{pb}$, contenido de $\mathrm{G} / \mathrm{C}$ de $50 \%$ a $60 \%$, temperatura de fusión de $52^{\circ} \mathrm{C}$ a $65^{\circ} \mathrm{C}$ y una lon-gitud del producto de entre 100 y 500 pb, con una diferencia mínima entre fragmentos de 50 pb (16). La especificidad in silico de los iniciadores se estimó con los algoritmos Blast y Clustalw ${ }^{\circledR}$ (URL). La estabilidad topológica y la formación de estructuras secundarias se evaluaron con los programas DNAstar ${ }^{\circledR}$ versión 3.04 y OligoAnalyze ${ }^{\circledR}$. Para la detección del serogrupo C2, se utilizaron los iniciadores descritos por Álvarez et al. (17). En el cuadro 2 se observan las características de los iniciadores utilizados en el estudio.

\section{Estandarización de la PCR-M}

Los iniciadores se evaluaron de manera individual mediante PCR convencional, con el fin de determinar el producto de amplificación esperado para cada par de iniciadores, utilizando las cepas pertenecientes a los serogrupos de importancia clínica escogidos para este estudio (B, C2, D y E) y los controles de especificidad.

Las condiciones de la PCR-M se escogieron de acuerdo con las recomendaciones dadas previamente por Henegariu et al., Álvarez et al. y Elnifro et al. (16-19), y con base en los resultados previamente descritos para la evaluación de los iniciadores.
Como control de amplificación interno, se utilizó la detección del gen invA de $S$. enterica; este gen está ubicado en la isla de patogenicidad 1 de Salmonella sp. y está presente en todos los serotipos. La amplificación se llevó a cabo en un termociclador Primus 96 plus MWG- Biotech (Vernon Hills, Illinois, USA).

Se tomaron alícuotas de $10 \mu \mathrm{l}$ de cada producto de PCR, los cuales fueron visualizados por electroforesis en geles de agarosa (Nusieve $3: 1 \AA$ ) al $2,5 \%$, corridos por dos horas y 30 minutos a 90 voltios en solución tampón TBE 1X, teñidos con SYBR Safe ${ }^{\circledR}$ (Invitrogen Carlsbad, CA, USA), visualizados y fotografiados en un analizador de imágenes EpiChemi Darkroom de UVP Biolmaging Systems (Upland, California, Estados Unidos). El tamaño de los fragmentos fue determinado por comparación con un marcador de peso molecular de $50 \mathrm{pb}$ por medio de Fermentas $\AA^{\circledR}$ (Ontario, Canadá).

\section{Determinación de la concentración mínima de ADN detectada por la PCR-M}

Se realizaron ocho diluciones seriadas del ADN de las cepas correspondientes a los serogrupos de estudio $(100,50,25,10,5,4,2$, $1 \mathrm{ng} / \mu \mathrm{l})$, partiendo de una dilución que contenía $100 \mathrm{ng} / \mathrm{\mu l}$ de ADN, la cual fue cuantificada por espectrofotometría. A este material se le realizó

Cuadro 2. Características de los iniciadores utilizados en este estudio.

\begin{tabular}{|c|c|c|c|c|c|c|}
\hline Iniciadores & $\begin{array}{c}\text { Blanco/ } \\
\mathbf{N}^{\circ} \text { acceso }\end{array}$ & $\begin{array}{l}\text { Longitud } \\
\qquad(\mathrm{pb})\end{array}$ & Secuencia 5'-3' & $\begin{array}{c}\text { Temperatura } \\
\text { de } \\
\text { anillamiento }\end{array}$ & $\begin{array}{c}\text { Tamaño } \\
\text { amplicón } \\
\text { (pb) }\end{array}$ & Posición \\
\hline $\begin{array}{l}\text { Grupo B -F } \\
\text { Grupo B-R }\end{array}$ & $\begin{array}{l}\text { rfbJ } \\
\text { AE008792 }\end{array}$ & $\begin{array}{l}28 \\
30\end{array}$ & $\begin{array}{l}\text { GTAAACATGCGATTAGAGCATGTATATG } \\
\text { GTAAACATGCGATTAGAGCATGTATATG }\end{array}$ & $\begin{array}{l}56 \\
55\end{array}$ & 152 & $\begin{array}{l}478-506 \\
600-630\end{array}$ \\
\hline $\begin{array}{l}\text { Grupo C2- }{ }^{*} \\
\text { Grupo C2-R* }\end{array}$ & $\begin{array}{l}\text { rfbJ } \\
\text { X619171 }\end{array}$ & $\begin{array}{l}20 \\
20\end{array}$ & $\begin{array}{l}\text { AATAGGCCGAAACAACATCG } \\
\text { CCGAGCCAACGATTATCAA }\end{array}$ & $\begin{array}{l}60 \\
62\end{array}$ & 502 & $\begin{array}{l}487-508 \\
815-836\end{array}$ \\
\hline $\begin{array}{l}\text { Grupo E-F } \\
\text { Grupo E-R }\end{array}$ & $\begin{array}{l}\text { Wzx } \\
X 60665\end{array}$ & $\begin{array}{l}20 \\
22\end{array}$ & $\begin{array}{l}\text { CTAATGATTTGCGGCGTCTC } \\
\text { CAGTGGGGAAGCTATTGCTGAT }\end{array}$ & $\begin{array}{l}61 \\
62\end{array}$ & 348 & $\begin{array}{l}517-536 \\
843-864\end{array}$ \\
\hline $\begin{array}{l}\text { Grupo D-F } \\
\text { Grupo D-R }\end{array}$ & $\begin{array}{l}\text { wzX } \\
\text { M65054 }\end{array}$ & $\begin{array}{l}20 \\
20\end{array}$ & $\begin{array}{l}\text { GCGTTGGGAGTGTGGTCTAT } \\
\text { AATGGGCAGTATTGCTACCG }\end{array}$ & $\begin{array}{l}54 \\
52\end{array}$ & 185 & $\begin{array}{l}431-450 \\
596-615\end{array}$ \\
\hline $\begin{array}{l}\operatorname{inv} A-F^{* *} \\
\operatorname{inv} A-R^{* *}\end{array}$ & $\begin{array}{l}\text { invA } \\
\text { M90846 }\end{array}$ & $\begin{array}{l}22 \\
22\end{array}$ & $\begin{array}{l}\text { AGAAGGGTCGTCGTTAGGACTG } \\
\text { CCAGACAGTGGTAAAGCTCATC }\end{array}$ & $\begin{array}{l}60 \\
60\end{array}$ & 450 & $\begin{array}{l}1023-1044 \\
1435-1456\end{array}$ \\
\hline
\end{tabular}

F: iniciador sentido; R.: iniciador antisentido; *: grupo C2, iniciadores diseñados por Álvarez et al. (20); ** invA: control interno de amplificación, iniciadores diseñados por Uzzau et al., datos sin publicarse. 
la PCR-M de serogrupo, con el fin de determinar la mínima cantidad de ADN (ng/ul) que puede detectar la prueba.

\section{Validación de la PCR-M}

Con el fin de determinar la concordancia entre los resultados obtenidos por la PCR-M con la prueba estándar de serotipificación (método de referencia), se realizó un estudio ciego utilizando 400 aislamientos clínicos escogidos al azar, los cuales fueron serotipificados previamente por el Laboratorio de Microbiología del Instituto Nacional de Salud de Colombia.

Estos 400 aislamientos fueron recuperados en agar IP® (Instituto Pasteur, París, Francia) y, posteriormente, se les realizó la extracción del ADN por el método de lisis con solución detergente, previamente descrito por Haque (15).

El tamaño de la muestra se calculó teniendo en cuenta los siguientes supuestos: sensibilidad y especificidad, 95\%; probabilidad de error, 5\%, e intervalo de confianza, 90\%. La sensibilidad y especificidad de cada PCR-M se determinaron usando el programa estadístico Epi-info 6.0. Una vez obtenidos los resultados de la PCR-M, éstos se enviaron al Instituto Nacional de Salud, con el fin de abrir la clave del estudio ciego, confirmar y analizar los resultados obtenidos por las dos pruebas.

Cuando se encontraron resultados incongruentes entre las pruebas, se repitió por duplicado la serotipificación y la PCR-M.

\section{Análisis de costos}

Se calculó el valor en pesos de cada prueba, teniendo en cuenta los costos directos e indirectos (reactivos, mano de obra, uso de equipos, energía).

\section{Resultados}

\section{Evaluación de iniciadores}

Se encontró que los iniciadores de serogrupo rfbJ y wzx fueron específicos para identificar cada uno de los serogrupos propuestos (B, C2, $D$ y E), debido a que no se presentaron reacciones cruzadas entre ellos. Sin embargo, el iniciador diseñado inicialmente para identificar el serogrupo C2 fue reemplazado por una secuencia previamente publicada por Álvarez et al. (20) (con tamaño de amplicón de 502 pb), ya que el iniciador que se diseñó produjo un amplicón de 348 pb, indistinguible del amplicón para el serogrupo E de $345 \mathrm{pb}$. En la figura $1 \mathrm{se}$ observan los tamaños de los amplicones para cada serogrupo evaluado por PCR convencional, utilizando serovares correspondientes a cada serogrupo.

\section{Estandarización de la PCR-M}

Luego de evaluar diferentes concentraciones de reactivos, iniciadores y ADN, y de haber probado diferentes gradientes de temperaturas de anillamiento de los iniciadores dentro del protocolo de amplificación, se obtuvieron las siguientes condiciones óptimas para la PCR-M.

Una mezcla de reacción que contenía un volumen final de $60 \mu \mathrm{l}$ compuesta por $45 \mu \mathrm{l}$ de PCR SuperMix® (Invitrogen, Brasil), $(0,88 \mathrm{mM}$

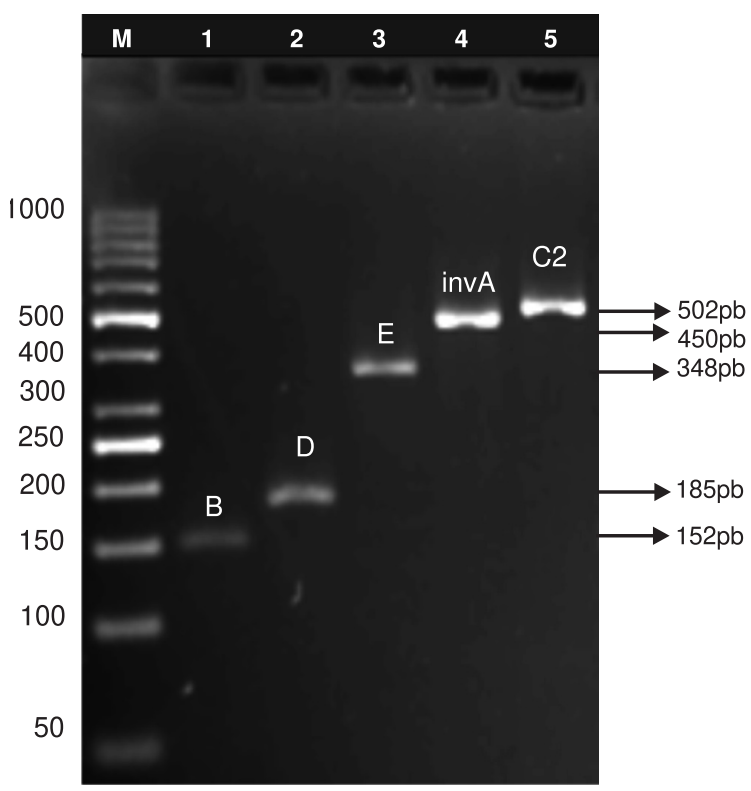

Figura 1. Amplicones obtenidos por PCR convencional en la evaluación de iniciadores para los serogrupos B, C2, D y E de Salmonella

Carril M: marcador de peso molecular: escalera de $50 \mathrm{pb}$; carril 1: S. typhimurium, serogrupo B; carril 2: $S$. typhi, serogrupo D; carril 3: S. Weltevreden, serogrupo E; carril 4: control interno de amplificación S. Weltevreden; carril 5: S. Newport, serogrupo C2. 
Tris- $\mathrm{HCl}, 2,2 \mathrm{mM} \mathrm{KCl}, 0,066 \mathrm{mM} \mathrm{MgCl}, 8,8$ $\mu \mathrm{M}$ de cada dNTP, $0,88 \mathrm{U}$ de Taq polimerasa recombinante estabilizada), $6 \mu \mathrm{l}$ de la mezcla de iniciadores $(B F w-R w 0,2 \mu \mathrm{M}, C 2 F w-R w 0,2$ $\mu \mathrm{M}, \mathrm{D} F w-R w 0,08 \mu \mathrm{M}, \mathrm{E} F w-R w 0,2 \mu \mathrm{M}$, invA $F w-R w 0,24 \mu \mathrm{M})$ y $9 \mu \mathrm{l}$ de ADN molde.

En cuanto a la temperatura de anillamiento de cada par de iniciadores dentro de la mezcla, se encontró que la óptima era de $58^{\circ} \mathrm{C}$.

En la PCR-M para la identificación de los serogrupos, los cinco pares de iniciadores se evaluaron en combinación, utilizando aislamientos de referencia pertenecientes a los serogrupos objeto del estudio, lo que permitió asegurar la especificidad de los productos de amplificación obtenidos. Cada serogrupo mostró un perfil único de bandas, con tamaños específicos de $152 \mathrm{pb}$ (serogrupo B), $185 \mathrm{pb}$ (serogrupo D), 348 pb (serogrupo E) y 502 pb (serogrupo C2); en cada perfil de serogrupo se incluyó el gen invA como control interno de la reacción, con un tamaño de $450 \mathrm{pb}$ (figura 2).

\section{Límite de detección de la PCR-M}

Luego de evaluar cada una de las diluciones del ADN, se determinó que el límite mínimo de detección de la prueba de PCR-M de serogrupo fue de $5 \mathrm{ng} / \mu \mathrm{l}$. Estos ensayos se realizaron por triplicado con el fin de establecer la reproducibilidad de la prueba. El límite máximo de ADN o concentración óptima para la prueba de PCR-M, fue de $100 \mathrm{ng} / \mu \mathrm{l}$, ya que con concentraciones mayores se observó en algunos casos inhibición de la PCR o la producción de bandas inespecíficas (no se muestran datos).

\section{Evaluación de la especificidad de la PCR-M de serogrupo}

Para examinar posibles reacciones cruzadas entre los iniciadores diseñados con diferentes géneros de la familia Enterobacteriaceae, (Proteus spp., Yersinia spp., E. coli, Klebsiella spp., Citrobacter spp., Shigella sp y Aeromonas spp.), se evaluó una cepa de cada una de estas enterobacterias, utilizando las condiciones previamente optimizadas para la PCR-M en la detección de serogrupos. Se encontraron los resultados esperados, ya que ninguna de estas bacterias mostró amplificación con ninguno de los iniciadores de la mezcla para identificar serogrupos, lo cual indica 100\% de especificidad de la PCR (no se muestran datos).

\section{Validación de la prueba de PCR-M}

Se encontró concordancia entre la PCR-M y la serotipificación tradicional en 386 de los 400 aislamientos evaluados (96,5\%) (cuadro 3).

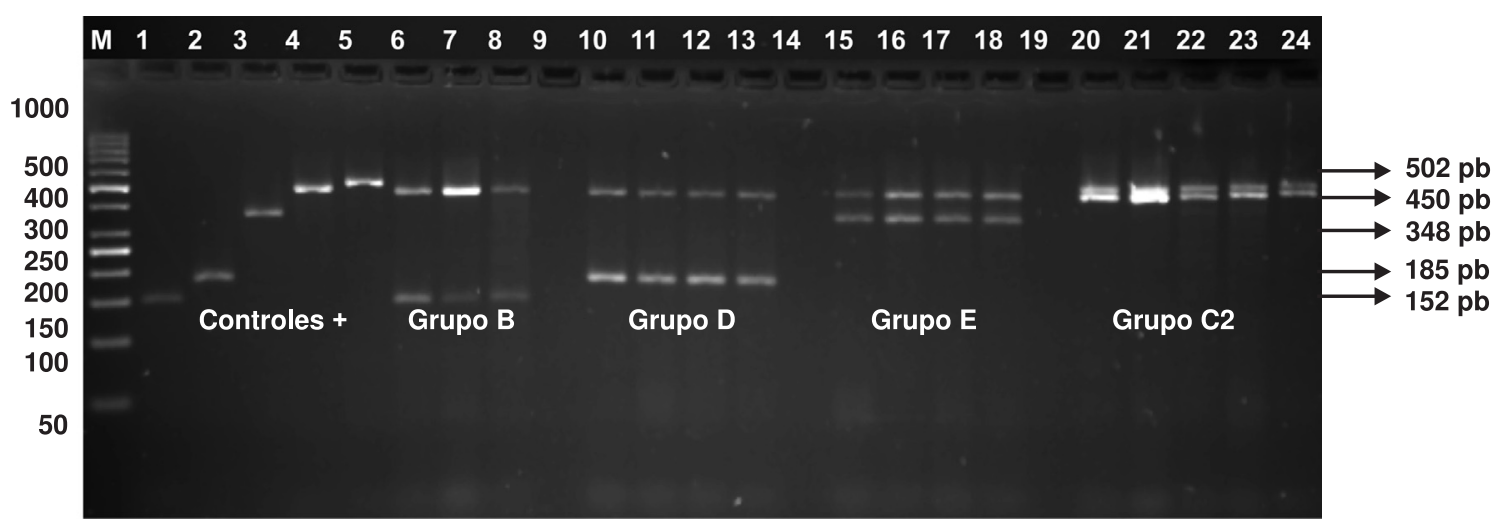

Figura 2. Resultados de la PCR múltiple para la identificación de los serogrupos B, C2, D y E de Salmonella

Carril M: marcador de peso molecular: escalera $50 \mathrm{pb}$; carriles 1-3,5: controles positivos de cada serogrupo: B, D, C2 y E. respectivamente; carril 4: control interno de amplificación invA; carriles 6-8: serotipos grupo B, Typhimurium, Derby, Sainpaul; carriles 10-13: serotipos grupo D, Typhi, Enteritidis, Dublin, Gallinarum; carriles 15-18: serotipos grupo E, Anatum, Uganda, Sinstorff, Weltevreden; carriles 20-24: serotipos grupo C2, Newport, Hadar, Kentucky, Muenchen, Manhattan; carriles 9, 14, 19: controles negativos. 
Hubo 14 aislamientos que no coincidieron en ambas tipificaciones, tres identificados como bacterias diferentes a Salmonella spp. y once no identificados por la serología tradicional, debido a que son aislamientos rugosos que han perdido la expresión del antígeno $\mathrm{O}$, pero que sí fueron identificados por PCR-M.

La sensibilidad y la especificidad encontradas para la identificación de los serogrupos C2 y E fueron de 100\%; para el serogrupo B, la sensibilidad fue de $98 \%$ y la especificidad de $99 \%$, y para el serogrupo D, la sensibilidad fue de $98 \%$ y la especificidad de $96 \%$.

\section{Costos}

El costo promedio de la serotipificación hasta serogrupo fue de Col\$ 40.000, que equivale aproximadamente a US\$22. El costo de la PCR-M de serogrupo fue de Col $\$ 30.000$, que equivalente aproximadamente a US\$16.

\section{Discusión}

En este estudio se desarrolló una metodología basada en la detección directa de los genes rfbJ, wzx, por PCR-M, para la identificación molecular de serogrupos de $S$. enterica de importancia clínica en Colombia (14).

Los resultados obtenidos muestran que la PCR-M para la detección de serogrupos de Salmonella es una buena alternativa para mejorar las limitaciones de la serotipificación tradicional, ya que el método molecular desarrollado fue sensible, específico, reproducible, costo-efectivo y de interpretación objetiva, lo cual sugiere que la tipificación molecular puede aplicarse para apoyar la serotipificación tradicional.

Los resultados de la validación de la prueba mostraron una congruencia entre el método molecular y el método tradicional de $96,5 \%$ $(n=386)$. Estos resultados indican altos valores de sensibilidad y especificidad para la nueva prueba molecular desarrollada.

Una de las limitaciones de la serotipificación se demuestra por la existencia de cepas que no pueden tipificarse debido a la pérdida del antígeno $\mathrm{O}$ (cepas rugosas) o porque no expresan alguno de los dos genes flagelares (21-23). Estas cepas no pueden identificarse por serotipificación tradicional o arrojan resultados inexactos, ya que este método depende de la expresión o exposición de los antígenos (23). Por el contrario, la PCR-M detecta las secuencias de ADN específicas, las cuales se encuentran presentes en el genoma aunque no se expresen $(21,24)$, lo cual representa una alternativa para la tipificación de estas cepas problema.

En la PCR-M se evaluó un par de iniciadores para la identificación del serogrupo C2, previamente publicados por Álvarez et al. (20), y tres pares de iniciadores diseñados en este estudio para la identificación de los serogrupos B, D y E.

Cuadro 3. Resultados de la comparación entre la PCR múltiple para serogrupos $B, C 2, D$ y $E$ frente a la serotipificación tradicional.

\begin{tabular}{lccc}
\hline Número de aislamientos & $\begin{array}{c}\text { Resultados de } \\
\text { serotipificación } \\
\text { tradicional }\end{array}$ & $\begin{array}{c}\text { Número de } \\
\text { aislamientos }\end{array}$ & $\begin{array}{c}\text { Resultados de } \\
\text { identificación } \\
\text { molecular }\end{array}$ \\
\hline 109 & $\mathrm{B}$ & 107 & $\mathrm{~B}$ \\
30 & $\mathrm{C}$ & $1^{*}$ & $\mathrm{D}$ \\
132 & $\mathrm{1}$ & 30 & $\mathrm{C} 2$ \\
115 & $\mathrm{D}$ & 129 & $\mathrm{D}$ \\
11 & $\mathrm{E}$ & $3^{*}$ & $\mathrm{~B}$ \\
3 & No identificadas & $9^{*}$ & $\mathrm{D}$ \\
& Bacterias diferentes a & $2^{*}$ & No identificadas \\
& Salmonella & & Bacterias diferentes a \\
\hline
\end{tabular}

* Identificación que no coincidió con ambas técnicas 
Estos iniciadores permitieron discriminar los serogrupos con un alto nivel de especificidad y sensibilidad, sin reacciones cruzadas con los aislamientos examinados, los cuales representan los serogrupos prevalentes en Colombia (25). Los resultados anteriores son congruentes con los publicados por Luk et al. (13) y HerreraLeón et al. (24), que corroboran la utilidad de las secuencias de los genes rfbJ y wzx como marcadores moleculares específicos para la detección de estos serogrupos en particular.

La serotipificación tradicional se considera el método de referencia para la identificación de serovares de Salmonella. Sin embargo, este método mostró resultados incongruentes cuando se realizaron repeticiones de los once aislamientos rugosos que habían sido previamente serotipificados y que no coincidieron con la tipificación por PCR-M; esto sugiere que la serotipificación no es 100\% específica.

Teniendo en cuenta estos resultados, la PCR-M podría aplicarse como método rutinario para laboratorios de tercer nivel y de salud pública que requieren identificar serogrupos de Salmonella en menos tiempo y a menor costo que la serotipificación tradicional.

El uso de esta PCR-M en alimentos y muestras clínicas debe explorarse para la detección directa del microorganismo, lo cual ya ha sido descrito por otros autores usando metodologías de amplificación de ADN (15,20,26,27).

Con el fin de continuar en el avance de esta investigación, se sugiere el uso de este método complementado con la identificación a nivel de genes que expresan antígenos flagelares, lo cual podría servir como base para la identificación de Salmonella a nivel de serovar, de importancia epidemiológica en Colombia.

\section{Conflicto de intereses}

Los autores declaran que no tienen ningún conflicto de intereses con la publicación de estos datos.

\section{Financiación}

Instituto Colombiano para el Desarrollo de la Ciencia (Colciencias) proyecto código 3256-
07-18105, Instituto Colombiano de Medicina Tropical-Universidad CES, Instituto Nacional de Salud.

\section{Referencias}

1. Popoff MY, Le Minor L. Antigenic formulas of the Salmonella serovars. Paris: Institut Pasteur; 2001.

2. Brenner FW, Villar RG, Angulo FJ, Tauxe R, Swaminathan B. Salmonella nomenclature. J Clin Microbiol. 2000;38:2465-7.

3. Kauffmann F. The bacteriology of Enterobacteriaceae. Baltimore: Williams \& Wilkins; 1966.

4. Fitzgerald C, Gheesling L, Collins M, Fields PI. Sequence analysis of the $\mathrm{rfb}$ loci, encoding proteins involved in the biosynthesis of the Salmonella enterica $\mathrm{O} 17$ and $\mathrm{O} 18$ antigens: serogroup-specific identification by PCR. Appl Environ Microbiol. 2006;72:7949-53.

5. Verma NK, Quigley NB, Reeves PR. O-antigen variation in Salmonella spp rfb gene clusters of three strains. J Bacteriol. 1998;170:103-7.

6. Liu D, Haase AM, Lindqvist L, Lindberg AA, Reeves PR. Glycosyl transferases of O-antigen biosynthesis in Salmonella enterica: identification and characterization of transferase genes of groups B, C2, and E1. J Bacteriol. 1993;175:3408-13.

7. Wyk P, Reeves PR. Identification and sequence of the gene for abequose synthase, which confers antigenic specificity on group B Salmonellae: homology with galactose epimerase. J Bacteriol. 1989;171:5687-93.

8. Liu D, Cole RA, Reeves PR. An O-antigen processing function for Wzx (RfbX): a promising candidate for O-unit flippase. J Bacteriol. 1996;178:2102-7.

9. Mortimer CK, Peters TM, Gharbia SE, Logan MJ, Arnold C. Towards the development of a DNA-sequence based approach to serotyping of Salmonella enterica. BMC Microbiol. 2004;4:31-40.

10. Karami A, Ranjbar R, Ahmadi Z, Safiri Z. Rapid detection of different serovares of Salmonella enterica by multiplex PCR. Iranian J Publ Health. 2007;36:38-42.

11. Soltani MJ, Shahhosseiny MH, Shahbazzadeh D, Karami V, Mirzahoseini H, Mahboudi F, et al. Selective amplification of prt, tyv, and invA genes by multiplex PCR for rapid detection of Salmonella typhi. Iranian J Publ Health. 2005;9:135-8.

12. Lim YH, Hirose K, Izumiya H, Arakawa E, Takahashi $\mathrm{H}$, Terajima J, et al. Multiplex polymerase chain reaction assay for selective detection of Salmonella enterica serovar Typhimurium. Jpn J Infect Dis. 2003;56:151-5.

13. Luk JM, Kongmuang U, Reeves PR, Lindberg AA. Selective amplification of abequose and paratose synthase genes $(r f b)$ by polymerase chain reaction for identification of Salmonella major serogroups (A, B, C2 and D). J Clin Microbiol. 1993;31:2118-23. 
14. Muñoz N, Agudelo Cl, Ovalle MV, Realpe MH. Vigilancia en red de la susceptibilidad antimicrobiana y de los serotipos de Salmonella spp., Shigella spp. y Vibrio cholerae O1, 1997-1999. Biomédica. 2000;20:210-7.

15. Haque A, Ahmed J, Qureshi JA. Early detection of typhoid by polimerase chain reaction. Ann Saudi Med. 1999;19:337-40.

16. Henegariu O, Heerema NA, Dlouhy SR, Vance GH, Vogt PH. Multiplex PCR: critical parameters and stepby-step protocol. Biotechniques. 1997;23:504-11.

17. Álvarez J, Sota M, Vivanco AB, Perales I, Cisterna R, Rementeria A, et al. Development of a multiplex PCR technique for detection and epidemiological typing of Salmonella in human clinical samples. J Clin Microbiol. 2004;42:1734-8.

18. Elnifro EM, Ashshi AM, Cooper RJ, Klapper PE. Multiplex PCR: optimization and application in diagnostic virology. Clin Microbiol Rev. 2000;13:559-70.

19. Malorny B, Hoorfar J, Bunge C, Helmuth R. Multicenter validation of the analytical accuracy of Salmonella PCR: towards an international standard. Appl Environ Microbiol. 2003;69:290-6

20. Olive DM, Bean P. Principles and applications of methods for DNA-based typing of microbial organisms. J Clin Microbiol. 1999;37:1661-9.

21. Curd H, Liu D, Reeves PR. Relationships among the O-antigen gene clusters of Salmonella enterica groups B, D1, D2 and D3. J Bacteriol. 1998;180:1002-7.
22. Hellerqvist CG, Rudén U. The group C2-type modification of the B-Type lipopolysaccharide in a hybrid between Salmonella groups B and C2. Eur J Biochem. 1972;25:96-101.

23. Wang L, Andrianopoulos K, Liu D, Popoff MY, Reeves PR. Extensive variation in the O-Antigen gene cluster within one Salmonella enterica serogroup reveals an unexpected complex history. J Bacteriol. 2002;184:166977.

24. Herrera LS, Ramiro R, Arroyo M, Díez R, Usera MA, Echeita MA. Blind comparison of traditional serotyping with three multiplex PCR for identification of Salmonella serotypes. Res Microbiol. 2007;158:122-7.

25. Muñoz N, Firacative C, Realpe ME, Patiño L, Gómez ME, Murcia LM, et al. Informe anual de la vigilancia fenotípica y molecular de Salmonella spp. en Colombia, 2007. Inf Quinc Epidemiol Nac. 2008;13:207-22.

26. Malkawi HI, Gharaibeh R. Rapid and simultaneous identification of two Salmonella enterica serotypes, Enteritidis and Typhimurium from chicken and meat products by multiplex PCR. Biotechnology. 2004;3:44-8.

27. Sánchez MM, Cardona-Castro N. Desarrollo y evaluación de una prueba de reacción en cadena de la polimerasa (PCR), utilizando la secuencia del gen hilA para diagnóstico de fiebre entérica por Salmonella spp. Biomédica. 2004;24:194-9. 